\title{
Study on intergenerational differences between the new generation of migrant workers and the first generation of migrant workers
}

\author{
Chen Suqiong \\ College of Economics Management \\ Shenyang Agricultural University \\ Shenyang, China \\ e-mail: aprilsu422@163.com
}

\begin{abstract}
The paper studies the intergenerational differences on education degree, marital status, work type, migrant flow distribution and remittance between the new generation migrant workers and the first generation migrant workers, based on the survey in Liaoning province. Study shows that the education degree of the new generation migrant workers is significantly higher than the first generation of migrant workers; the unmarried proportion is much higher than the first generation of migrant workers; the first generation of migrant workers are more like to choose the outside the county and in the province of flow type; most of the new generation migrant workers choose to become skilled workers; compared to the first generation of the rural labor, the amount of the remittance of the new generation migrant workers is less and most of their salaries are used by their own consumption in the city.
\end{abstract}

Keywords-rural labor tranfer; intergenerational difference; the new generation migrant workers; the first generation migrant workers

\section{INTRODUCTION}

Since reform and opening up, along with industrialization and urbanization, the transfer of rural labor has become a fairly common phenomenon in China. According to the migrant workers statistics monitoring survey report of the National Bureau of Statistics, there were the total 163360000 migrant workers in 2012. According to the age structure of migrant workers in 2011, the survey shows that migrant workers of 16-20 years accounted for $6.3 \%$, of $21-30$ year old accounted for $32.7 \%$, of $31-40$ years accounted for $22.7 \%$, of $41-50$ years accounted for $24.0 \%$, more than 50 years old accounted for $14.3 \%$, mainly young migrant workers, the new generation of migrant workers became the subject. The new generation of migrant workers became the focus and hot research field of migrant workers in China. Accurately grasp the population characteristics of the new generation of migrant workers and its relationship with the first generation of migrant workers on intergenerational differences has become the urgent needs to establish the related policy.

\section{DATA SOURCES AND THE BASIC CHARACTERISTICS OF} FARMERS

This paper used data from two questionnaire survey in Liaoning Province. The first sample survey of households in main grain-producing areas in Liaoning Province, using the form of the questionnaire, in July 2010, asked respondents farmers and family members characterized, large-scale land status, type and cost of crop production processes, and so on. In the process of investigation adopted stratified random sampling to select the sample of households. First, based on the economic conditions of the township and distance from the county, we selected four towns from each region randomly. Then, based on scale selected 4-5 sample villages in each township randomly, last selected 5-10 peasant households in each sample village randomly. If the sample drawn by the farmer is not at home in the survey, take the alternative method of adjacent unit. Finally we obtained 305 questionnaires, including 288 valid questionnaires, accounting for $94.43 \%$.

Taking into account sample data in the July 2010 survey, and the investigation focused on the main grain-producing areas reasons, the research group conducted a supplementary survey data during the winter vacation of 2012. This survey questionnaire is similar to the previous survey questionnaire in 2010, mainly asked respondents farmers and family members characterized, large-scale land status, type and cost of crop production processes, and so on. Finally we obtained 210 questionnaires, including 203 valid questionnaires, accounting for $96.67 \%$.

In two survives we obtained 284 migrant workers in 2010, including 160 the new generation of migrant workers accounting for $56.34 \%, 124$ the first generation of migrant workers, accounting for $43.66 \%$. The average age of migrant workers is 32.58 , the average age of accept education time is 8.85 years.

\section{ANALYSIS OF CHARACTERISTICS OF CENOZOIC MIGRANT WORKER}

\section{A. Age and Education Status}

In the survey we found that age range of the new generation of migrant workers is $16-30$ years old, the average age of 23.55 years. The extent of the new generation of migrant workers by education, primary school education and below accounted for $8.13 \%$, junior high school education accounted for $61.88 \%$, high school and technical secondary school education accounted for $19.38 \%$, college degree and above accounted for $10.63 \%$.The proportion of junior high school degree or above is account for $91.87 \%$ of the total. From received formal education period, the new generation of migrant worker force, on average, the duration of 9.58 years of normal education, which fully shows the new 
generation migrant worker force is a group with higher education as a whole.

\section{B. Gender and Marital Status}

Male are 108 people, accounting for $67.5 \%$, women are 52 people, accounting for $32.5 \%$, converted into sex ratio, sex ratio of the new generation of migrant workers is 2.08 . This conclusion is different with Sun Yat-Sen university team in a 2006 survey of the Pearl River Delta 9 cities of migrant workers, which new generation female migrant workers accounted for $55.6 \%$ in the Pearl River Delta. As economically developed Pearl River Delta region, especially the consumer goods industry and service industry develops rapidly, and Liaoning Old Industrial Base of economic development exists obvious difference between two places, resulting in two places there are significant differences in gender structure of rural migrant workers.

From the point of marital status, the number of unmarried new generation of migrant workers is 90 , accounting for $56.25 \%$, the number of married is 68 , accounting for $43.50 \%$. The ration of unmarried men in new generation of migrant workers is $67.59 \%$, the proportion of women is $32.69 \%$, but the ration of married women in the new generation of migrant workers is $63.46 \%$, only $32.41 \%$ of men. This shows that in the rural the new generation of women migrant workers are more married women.

TABLE I. GENDER AND MARITAL STATUS OF THE NEW GENERATION OF MIGRANT WORKERS

\begin{tabular}{|c|c|c|c|c|}
\hline \multirow{2}{*}{} & \multicolumn{2}{|c|}{ male } & \multicolumn{2}{c|}{ female } \\
\cline { 2 - 5 } & number & percentage (\%) & number & percentage (\%) \\
\hline unmarried & 73 & 67.59 & 17 & 32.69 \\
\hline married & 35 & 32.41 & 33 & 63.46 \\
\hline divorced & 0 & 0 & 2 & 3.85 \\
\hline total & 108 & 100 & 52 & 100 \\
\hline
\end{tabular}

\section{Work Types}

The new generation of migrant workers is not like their parents did the work mainly concentrated in the construction site, they have more choice space. Work types of the new generation of men migrant workers mainly focused on ligong, odd jobs, waitress, vendors (no fixed location), salesman, low-skilled workers (such as a driver, cook, etc.), highly skilled workers (such as turner, fitter, bricklayer, computer operator, etc.) and so on seven types, in which the number of highly skilled workers up to 37 people, accounting for $34.26 \%$, followed by the number of odd jobs is 24 , accounted for $22.22 \%$, ligong and low-skilled workers, accounting for $12.04 \%$.

There is an obvious difference on work types between the new generation of women migrant workers and the male workers force. Most the new generation of women migrant workers engaged in the type of job is the waiter, accounting for $46.15 \%$, followed by low-skilled workers, accounting for $17.31 \%$, the number of women engaged in management is 4 , accounting for $3.85 \%$. Overall, the new generation of men migrant workers are more inclined to learn a technology, as either high or low skills of skilled workers, while women are more engaged in service class work such as waiter and the clerk and so on
TABLE II. WORK TYPES OF THE NEW GENERATION OF MIGRANT WORKERS

\begin{tabular}{|l|c|c|c|c|}
\hline & \multicolumn{2}{|c|}{ male } & \multicolumn{2}{c|}{ female } \\
\cline { 2 - 5 } & number & $\begin{array}{c}\text { percentage } \\
\text { (\%) }\end{array}$ & number & $\begin{array}{c}\text { percentage } \\
\text { (\%) }\end{array}$ \\
\hline ligong & 13 & 12.04 & 0 & 0 \\
\hline odd job & 24 & 22.22 & 2 & 3.85 \\
\hline waiter & 8 & 7.41 & 24 & 46.15 \\
\hline $\begin{array}{l}\text { small vendors } \\
\text { (no fixed place) }\end{array}$ & 2 & 1.85 & 2 & 3.85 \\
\hline salesman & 11 & 10.19 & 0 & 0 \\
\hline $\begin{array}{l}\text { clerk (such as secretarial, } \\
\text { accounting, office staff) }\end{array}$ & 0 & 0 & 7 & $13.46 \%$ \\
\hline fixed small shop owners & 0 & 0 & 2 & $3.85 \%$ \\
\hline $\begin{array}{l}\text { low-skilled workers (such } \\
\text { as drivers, cooks etc.) }\end{array}$ & 13 & 12.04 & 9 & 17.31 \\
\hline $\begin{array}{l}\text { highly skill workers (such } \\
\text { as turner, fitter, bricklayer, } \\
\text { computer operator etc.) }\end{array}$ & 37 & 34.26 & 2 & 3.85 \\
\hline management & 0 & 0 & 4 & 7.69 \\
\hline total & 108 & 100 & 52 & 100 \\
\hline
\end{tabular}

\section{Migrant Flow Distribution}

In the new generation of migrant workers, the number of workers who choose to work in the city is 84 , accounting for $52.50 \%$, the number of workers who work in Shenyang is 28, accounting for $17.50 \%$, only 6 workers choose to flow to other provinces, accounting for $3.75 \%$.The new generation of migrant workers, who work in county outside rural accounted for $26.25 \%$, who choose to flow province outside the county accounting for $70 \%$, who choose to flow across the province accounting for only $3.75 \%$. Further, gender and flow distribution of the new generation of migrant workers combined analysis, whether female or male who choose to work in the municipal city reached more than $50 \%$.

TABLE III. MIGRANT FLOW DISTRIBUTION OF THE NEW GENERATION OF MIGRANT WORKERS

\begin{tabular}{|c|c|c|c|c|}
\hline & \multicolumn{2}{|c|}{ male } & \multicolumn{2}{c|}{ female } \\
\cline { 2 - 5 } & number & percentage (\%) & number & percentage (\%) \\
\hline town & 18 & 16.67 & 9 & 17.31 \\
\hline county seat & 13 & 12.04 & 2 & 3.85 \\
\hline city & 58 & 53.70 & 26 & 50.00 \\
\hline provincial capital & 17 & 15.74 & 11 & 21.15 \\
\hline other provinces & 2 & 1.85 & 4 & 7.69 \\
\hline total & 108 & 100 & 52 & 100 \\
\hline
\end{tabular}

\section{E. Remittance and Its Purpose}

Remittances statistics of the new generation of migrant workers found that the number of labors who remittance amount between $0-5000$ is 78 , accounting for $48.75 \%$, the number of labors who remittance amount between 500010000 is 25 , accounted for $15.63 \%$, remittance within the range of $10000-20000$ accounted for $15 \%$, no remittance workers earn all the money is 12 , accounting for $7.50 \%$, and the number of labors who remittance between 30000-50000 is only 5 , accounting for $3.13 \%$. Thus, the new generation of migrant workers remittances below 10000 accounted for $71.88 \%$, the income of new generation of migrant workers is more for their own consumption. 
TABLE IV. REMItTANCE OF the NEW GENERAtion of Migrant WORKERS

\begin{tabular}{|c|c|c|c|c|}
\hline & \multicolumn{2}{|c|}{ male } & \multicolumn{2}{c|}{ female } \\
\cline { 2 - 5 } & number & percentage (\%) & number & percentage (\%) \\
\hline 0 & 10 & 9.26 & 2 & 3.85 \\
\hline $0-5000$ & 45 & 41.67 & 33 & 63.46 \\
\hline $5000-10000$ & 14 & 12.96 & 11 & 21.15 \\
\hline $10000-20000$ & 20 & 18.52 & 4 & 7.69 \\
\hline $20000-30000$ & 16 & 14.81 & 0 & 0 \\
\hline $30000-50000$ & 3 & 2.78 & 2 & 3.85 \\
\hline more than 50000 & 0 & 0 & 0 & 0 \\
\hline total & 108 & 100 & 52 & 100 \\
\hline
\end{tabular}

Further, gender and remittances of the new generation of migrant workers combined analysis, whether female or male the maximum remittances amount of all range is 5000-10000, the proportion of female remittance amount in this range as high as $63.46 \%$.

The main remittance of the new generation migrant workers is used for home subsidy, accounted for $41.62 \%$, followed by saving, accounted for $39.59 \%$, only $3.05 \%$ used for purchase of agricultural machinery to their family.

TABLE V. Purpose OF REMitTANCE OF THE NEW GENERATION OF MIGRANT WORKERS

\begin{tabular}{|c|c|c|}
\hline & number & percentage (\%) \\
\hline home subsidy & 82 & 41.62 \\
\hline build or repair the house & 9 & 4.57 \\
\hline Purchase of agricultural machinery & 6 & 3.05 \\
\hline saving & 78 & 39.59 \\
\hline used for agricultural production & 22 & 11.17 \\
\hline total & 197 & 100 \\
\hline
\end{tabular}

IV. COMPARISON OF GENERATIONAL DIFFERENCES IN THE NEW GENERATION MIGRANT WORKERS AND THE FIRST GENERATION OF MIGRANT WORKERS

\section{A. Generational Differences in Education Degree}

The new generation of migrant workers received formal education for an average of 9.58 years, while the first generation of migrant workers received formal education for an average of 8.11 years, there is a difference of 1.47 years between them. In the new generation of migrant workers force, the number of workers who received primary school education level and below accounted for only $8.13 \%$, accounted for $61.88 \%$ of junior high school, accounting for $19.38 \%$ of high school and technical secondary school, college and above accounted for $10.63 \%$, while in the first generation migrant workers force, the proportion of workers whose education level primary school and below, junior high school, high school and technical secondary school, college and above were $33.06 \%, 51.61 \%, 12.90 \%$ and $2.42 \%$. Education level of the new generation of migrant workers was significantly higher than the first generation of migrant workers; there are significant generational differences in education degree.

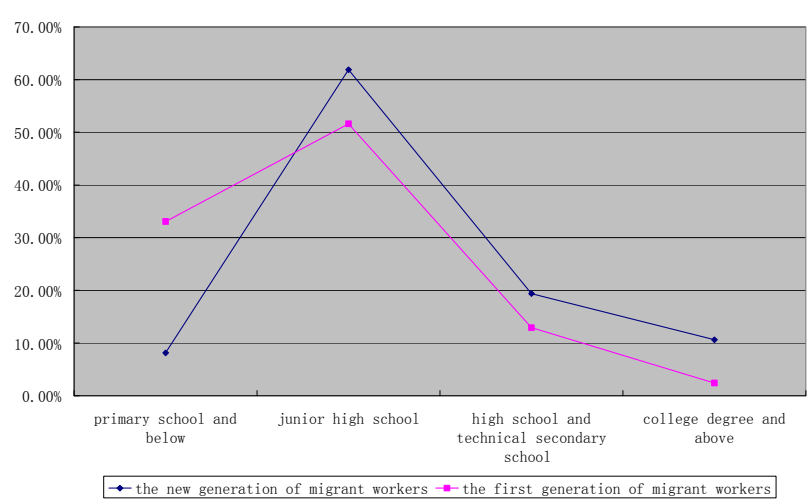

Figure 1 Differences of Education between the New Generation of Migrant Workers and the First Generation of Migrant Workers

\section{B. Generational Differences in Marital Status}

Unmarried population proportion of the new generation of migrant workers reaches $56.25 \%$, married proportion is $42.50 \%$, while in the first generation of migrant workers, unmarried proportion is only $5.65 \%$, the proportion of married as high as $92.74 \%$. The proportion of unmarried new generation of migrant workers is much higher than the first generation of migrant workers. This is closely related to the fact that the age difference between the new generation of migrant workers and the first generation of migrant workers, but there are also some other reasons. Such as Liu Chuanjiang (2010) considered that compared to the first generation of migrant workers, the concept of marriage of the new generation of migrant workers is closer to citizens, the idea of early marriage and early child-bearing gradually faded, the proportion of early marriage and early childbearing gradually declined; the first generation of migrant workers has higher expectations for the future, relatively strong desire for self-development. In general, they are reluctant to prematurely entering marriage and childbearing phases, most of them who are under enormous pressure, both unwilling to return to rural areas, and yet to gain a firm foothold in urban, so the marriage and childbearing is not on the agenda.

TABLE VI. MARITAL STATUS CONTRAST THE NEW GENERATION OF MigRANT WORKERS WITH THE FIRST GENERATION OF MIGRANT WORKERS

\begin{tabular}{|c|c|c|c|c|}
\hline \multirow{2}{*}{} & \multicolumn{2}{|c|}{$\begin{array}{c}\text { the new generation } \\
\text { of migrant workers }\end{array}$} & \multicolumn{2}{c|}{$\begin{array}{c}\text { the first generation } \\
\text { of migrant workers }\end{array}$} \\
\cline { 2 - 5 } & number & percentage (\%) & number & percentage (\%) \\
\hline unmarried & 90 & 56.25 & 7 & 5.65 \\
\hline married & 68 & 42.50 & 115 & 92.74 \\
\hline divorced & 2 & 1.25 & 0 & 0 \\
\hline widowed & 0 & 0 & 2 & 1.61 \\
\hline total & 160 & 100 & 124 & 100 \\
\hline
\end{tabular}

\section{Generational Differences in Work Types}

The new generation of migrant workers force engaged in highly skilled workers in the proportion of $24.38 \%$ is the highest, followed by the waiter accounted for $20 \%$, while the first generation of migrant workers engaged in high-skilled workers, ligong and odd jobs, the three kinds of work of the 
top three, the proportion is $25.81 \%, 25 \%$ and $16.94 \%$ respectively. This shows that although the new generation of migrant workers and the first generation of migrant workers are still focused on the job at the end of the queue of professional work, engaged in industrial workers, business people, service personnel, etc., but it still has a obvious generational differences between them, the new generation of migrant workers is more choice to learn an independent operation technology, such as computer operations, welding, driving a car, repair car, cooks and so on, to become a highly skilled worker or low-skilled worker, rather than like they fathers, the first generation of migrant workers, more is to engage in ligong and odd jobs such heavy work on construction sites.

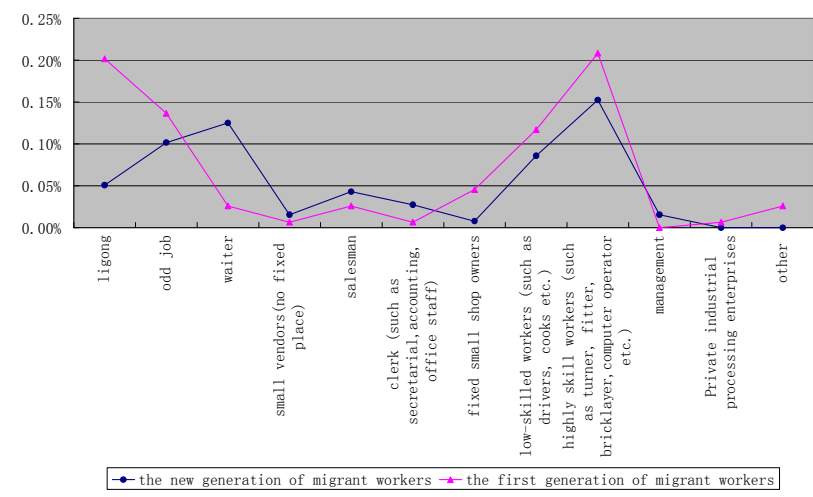

Figure 2 Work Types Contrast the New Generation of Migrant Workers with the First Generation of Migrant Workers

\section{Generational Differences in Migrant Flow Distribution}

From the perspective of a migrant flow distribution, intergenerational difference is obvious. The proportion of the new generation of migrant workers who flow for municipal city is up $53.50 \%$, the proportion of workers who flow for capital city, accounting for $17.50 \%$, but the proportion of first generation migrant who flow for capital city is the highest, accounting for $31.45 \%$.The proportion of the new generation of migrant workers who short distance flow is 5.2 percentage points lower than the first generation of migrant workers, the proportion of long distance interprovincial flow is small, also is 7.54 percentage points lower than the first generation of migrant workers. This shows that compared to the first generation of migrant workers, the new generation of migrant workers is more inclined to choose type of flow within the provincial and outside the county.

The new generation of migrant workers prefers to work in the big city in the province where more jobs and better opportunities for personal development, while older the first generation of migrant workers either the bias in the employment in the township and county where close to home, or bias in the long distance inter-provincial flow with relatively high income.

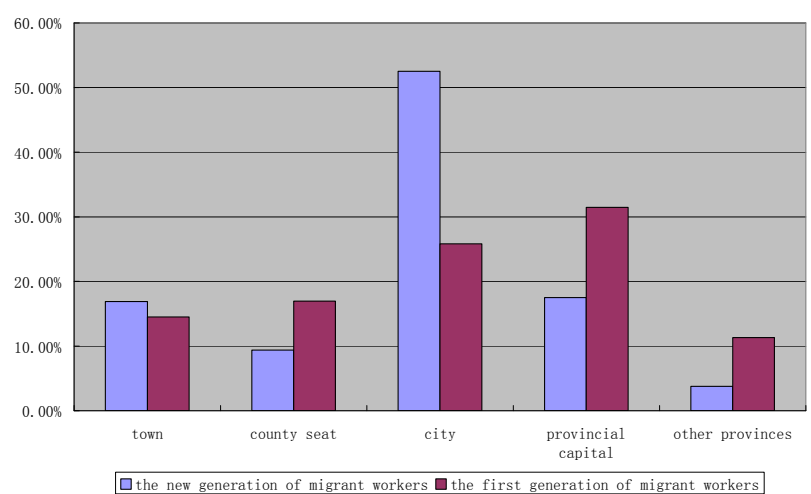

Figure 3 Migrant Flow Distribution Contrast the New Generation of Migrant Workers with the First Generation of Migrant Workers

\section{E. Generational Differences in Remittance}

There is an obvious generational difference in remittances amount between the new generation of migrant workers and the first generation of migrant workers. The proportion of the new generation of migrant workers whose remit amount of 10000 and below higher than the first generation of migrant workers 32.36 percent points. While the proportion of first-generation migrant workers who the amount of remittances more than 10,000were less than the proportion of the first generation of migrant workers. This shows that income of the new generation of migrant workers is more for their own consumption, so remittances is relatively less, and it associated with migrant purpose is to change the their life condition and the pursuit of their own development, not just with money economic motivation, while income of the first generation of migrant workers is more used remittances to meet its profitable economic motivation.

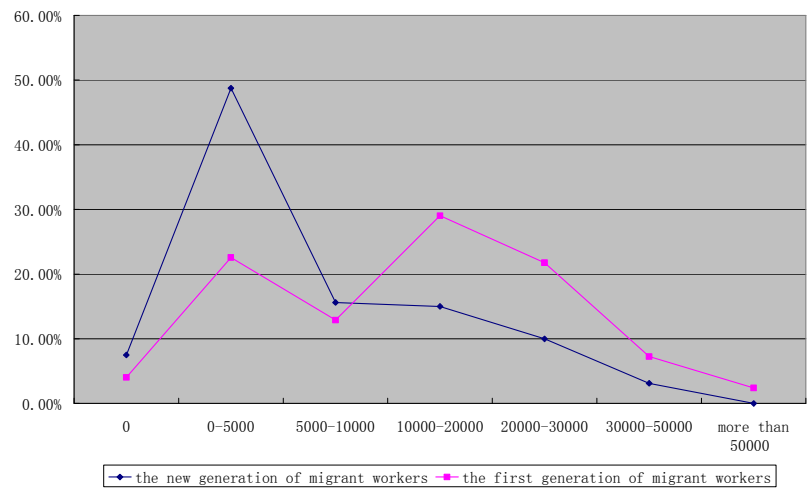

Fig.4 Remittance Contrast the New Generation of Migrant Workers with the First Generation of Migrant Workers

\section{CONCLUSIONS}

This study to analyze the basic characteristics of the new generation migrant workers, and to compare the intergenerational difference between the new generation migrant workers and the first generation migrant workers, based on the survey in Liaoning province. Studies show that new generation migrant workers' average age was 23.55 years, in general, men in a greater proportion than women 
and the unmarried are account for $56.25 \%$. The average year of education is 9.58. The new generation migrant workers are more likely to learn a foreign technology, to become a high(low) skilled worker, whereas women are more engaged in service work such as waiter or officials. The flow of new generation migrant workers tend to be over long distances where is in the province and outside the county. The income of the new generation of migrant workers is more for their own consumption. Due to the different growth environment, there are significant intergenerational differences between the first generation of migrant workers and the new generation of migrant workers. Looking from the level of education, the education of the new generation migrant workers is significantly higher than the first generation of migrant workers; Looking from the marital status, the unmarried proportion is much higher than the first generation of migrant workers; From the migrant flow distribution, they more likely choose the outside the county and in the province of flow type, rather than the first generation of migrant workers preference township county within the flow or flow across the province; From the type of the work, most of them choose to become skilled workers such as computer operator, Turner, and so on, which is different that most of the first generation of the rural workers force engaged in ligong and odd jobs; Looking from the remittance amount, compared to the first generation of the rural workers, the percentage of their remittances are less. Meanwhile the amount of the remittance is less and most of their salaries are used by their own consumption in the city.

\section{ACKNOWLEDGMENT}

We thanks youth project supported by National Science Foundation of china (Grant No: 71303159), and project supported by Science Foundation of Ministry of Education of China (Grant No:11YJC630018).

\section{REFERENCES}

[1] Duan Cheng-rong and Ma Xue-yang, "A Study on the New Situation of the Younger Generation of Farmer-turned Migrant Workers in China,” Population \& Economics, Apr,2011,pp.16-22. (in Chinese)

[2] Hu Feng and Wang Qiwen, “An Analysis of Determinants of Remittances of China's Rural Migrants-Application of Interval Regression Model,”Statistical Research, vol.24, Oct.2007, pp.2025.(in Chinese)

[3] Knight,Yueh, "Job mobility of residents and migrants in urban China,” Journal of Comparative Economics,vol.32, 2004,pp.637-660.

[4] Rozelle, S.Taylor, J.E.de Brauw.A, "Migration, Remittances and Agricultural Productivity in China," American Economic Review, vol.89,Feb.1999, pp.287-291.

[5] Wang Chunguang, "Social Identity of the New Generation of Rural Hobo and Merger of Urban and Rural,"Sociological Research, Mar.2001, pp.63-76.(in Chinese)

[6] Zhao YH "Labor migration and returns to rural education in China," American Journal of Agricultural Economics,Apr.1997,pp.1278-1287. 